\title{
Clinical efficacy and safety of HX575, a biosimilar recombinant human erythropoietin, in the management of anemia
}

This article was published in the following Dove Press journal:

Biosimilars

5 September 2012

Number of times this article has been viewed

\author{
Ivo Abraham ${ }^{1,2,3}$ \\ Karen MacDonald ${ }^{2}$ \\ 'Department of Pharmacy Practice \\ and Science, and Center for Health \\ Outcomes and PharmoEconomic \\ Research, University of Arizona, \\ Tucson, Arizona; ${ }^{2}$ Department of \\ Family and Community Medicine, \\ University of Arizona, Tucson, Arizona; \\ ${ }^{3}$ Matrix 45, Tucson, Arizona, USA
}

Correspondence: Ivo Abraham

Center for Health Outcomes and PharmacoEconomic Research, University of Arizona, 1295 N Martin,

Tucson, AZ 8572I, USA

$\mathrm{Tel}+\mathrm{I} 5206264425$

$\mathrm{Fax}+\mathrm{I} 5206267355$

Email abraham@arizona.pharmacy.edu

\begin{abstract}
Since the expiration of the patent for epoetin alfa in Europe in 2004, the European Medicines Agency has approved three biosimilar erythropoietins. Using the European Medicines Agency's European Public Assessment Reports and scientific publications, we review the evidence regarding the clinical efficacy and safety of HX575 (Sandoz/Novartis) relative to the originator product Eprex/Erypo (Johnson \& Johnson). Clinical efficacy is assessed as a function of therapeutic equivalence of a biosimilar and originator product, while safety is evaluated in terms of immunogenicity, venous thromboembolism, and mortality. Five studies that examined chronic renal failure and oncology populations are reviewed. In the renal setting, these studies include a randomized controlled trial on $\mathrm{Hb}$ maintenance in patients receiving long-term hemodialysis, a randomized safety trial in patients with chronic kidney disease not yet requiring renal replacement therapy, and a post-approval saftey commitment study. Studies in the cancer setting include a clinical validation study in patients with solid tumors receiving antineoplastic chemotherapy and a retrospective clinical audit of Binocrit in routine clinical practice. Based on available therapeutic equivalence and safety data, the clinical and safety outcomes of treatment with HX575 are likely to be similar to those of the originator product Eprex/Erypo. Both products can be considered interchangeable in the management of anemia in the approved indications, and patients transferred from the reference product to the biosimilar product are expected to show the same efficacy and safety outcomes. There is no evidence of the interchangeability of HX575 with other biosimilar or originator erythropoietins other than Eprex/Erypo. In keeping with European Medicines Agency guidance about traceability, it is recommended that clinicians document the product prescribed by its commercial name, especially when switching patients from an originator to a biosimilar or vice versa.
\end{abstract}

Keywords: Biosimilar, biosimilar pharmaceuticals, efficacy, erythropoietin, recombinant proteins, safety

\section{Introduction}

Anemia is a condition characterized by low red blood cell (or erythrocyte) counts and low hemoglobin $(\mathrm{Hb})$ levels in the blood and results in insufficient oxygen supply to organs. Red blood cell production is regulated by endogenous (or human) erythropoietin, a cytokine for erythrocyte precursors in the bone marrow that is produced mainly by the kidneys. The gene for this hematopoietic growth factor was isolated and characterized for research and production in $1985 .{ }^{1}$ Exogenous erythropoietin is produced by means of recombinant DNA technology. Following a combined Phase I and Phase II clinical trial, ${ }^{2}$ epoetin alfa (Epogen/Procrit, Amgen, Thousand Oaks, CA) was first approved for therapeutic use in the US in June of 1989 and has been marketed since as Epogen/Procrit (Amgen). Soon thereafter, the European 
Medicines Agency (EMA) authorized the product in Europe, where it is available as Eprex/Erypo (Johnson \& Johnson, New Brunswick, NJ).

On June 21, 2007 the EMA approved HX575 (Sandoz, Princeton, NJ), a biosimilar version of epoetin alfa, which is marketed mainly as Binocrit, but also as Abseamed and Epoetin Alfa Hexal. As detailed further in Table 1, in the renal setting, HX575 is approved for patients with chronic renal failure on hemo- or peritoneal dialysis or patients with advanced renal disease not yet on renal replacement therapy. In the cancer setting, HX575 is indicated for patients with solid tumors or patients with malignant lymphoma or multiple myeloma receiving chemotherapy and at risk for transfusion. The HX575 label also includes patients participating in autologous blood pre-donation programs so as to increase the yield, and in patients undergoing major elective orthopedic surgery to reduce their exposure to allogeneic blood transfusion. Contraindications for HX575 as specified in the EMA label are listed in Table 2.

A biosimilar, or "similar biological medicinal product" according to the European regulatory term, is a biologic agent that is highly similar in terms of quality, safety, and efficacy to an authorized reference biological medicine (often referred to as the originator product). Biosimilar erythropoietins are structurally complex proteins with significant micro-heterogeneity, produced by genetically modified living cells, and difficult to produce and purify. ${ }^{3}$ Manufacturing processes are complex in terms of choice of cell type and production, purification, and formulation methods. These processes influence the quality, purity, biological parameters, and clinical activity of the final product. In turn, this affects the efficacy and safety of a given biosimilar. ${ }^{4}$ According to Schellekens, "even if the biosimilar product has the same gene sequence, vector, host cell line, culture conditions and purification methods" as the reference protein, "it can still differ substantially in its biological and clinical properties". ${ }^{3}$ For instance, two EMA-approved biosimilar erythropoietins (Hx575 and SB309) have been found to have the same or better level of quality as the reference innovator Eprex/Erypo (Johnson \& Johnson). ${ }^{5}$

\section{Scope and approach}

This article, the first in a series of reviews of EMA-approved biosimilar erythropoietins, evaluates and summarizes evidence regarding the clinical efficacy and safety of the biosimilar erythropoietin agent HX575. The emphasis is on clinical results and the translation of late-stage clinical development research to the point of care. Thus this review focuses on controlled pre- and post-authorization and post-approval observational studies involving patients. The review does not cover quality evaluations, pre-clinical investigations, and early-stage clinical studies with healthy volunteers or patients. It is assumed that late-stage clinical studies would not have occurred in the absence of acceptable technical and scientific evidence of the chemical, pharmaceutical, and biological aspects of drug substance and drug product, non-clinical pharmacology and toxicology, clinical pharmacokinetics and pharmacodynamics, and safety in human subjects in the early stage pharmacokinetics/ pharmacodynamics studies.

The primary sources of evidence for this review are the EMA's European Public Assessment Report (EPAR) documents for HX575 as posted on the EMA website as of 3 January $2012 .{ }^{6}$ We also consulted articles published in peer-reviewed biomedical journals. Abstracts and posters were excluded because of the inherent limits in the depth

Table I Therapeutic indications for Binocrit as approved by the EMA

\begin{tabular}{|c|c|}
\hline Chronic renal insufficiency & $\begin{array}{l}\text { Treatment of symptomatic anemia associated with chronic renal failure in adult and pediatric patients on hemodialysis. } \\
\text { Treatment of symptomatic anemia associated with chronic renal failure in adult patients on peritoneal dialysis. } \\
\text { Treatment of severe anemia of renal origin accompanied by clinical symptoms in adult patients with renal insufficiency } \\
\text { not yet undergoing dialysis. }\end{array}$ \\
\hline Cancer & $\begin{array}{l}\text { Treatment of anemia and reduction of transfusion requirements in adult patients receiving chemotherapy for solid } \\
\text { tumors, malignant lymphoma or multiple myeloma, and at risk of transfusion as assessed by the patient's general status } \\
\text { (eg, cardiovascular status, pre-existing anemia at the start of chemotherapy). }\end{array}$ \\
\hline $\begin{array}{l}\text { Autologous predonation } \\
\text { program }\end{array}$ & $\begin{array}{l}\text { To increase the yield of autologous blood from patients in a predonation program. Use must be balanced against } \\
\text { the reported risk of thromboembolic events. Treatments should only be given to non-iron deficient patients with } \\
\text { moderate anemia (hemoglobin between } 10 \text { and } 13 \mathrm{~g} / \mathrm{dL} \text { ), if blood saving procedures are not available or insufficient } \\
\text { when the scheduled major elective surgery requires a large volume of blood ( } 4 \text { or more units of blood for females or } \\
5 \text { or more units for males). }\end{array}$ \\
\hline $\begin{array}{l}\text { Major elective orthopedic } \\
\text { surgery }\end{array}$ & $\begin{array}{l}\text { To reduce exposure to allogeneic blood transfusions in adult non-iron deficient patients prior to major elective } \\
\text { orthopedic surgery, having a high perceived risk for transfusion complications. Use should be restricted to patients } \\
\text { with moderate anemia (hemoglobin between } 10 \text { and } 13 \mathrm{~g} / \mathrm{dL} \text { ) who do not have an autologous predonation program } \\
\text { available and with expected moderate blood loss }(900 \text { to } 1800 \mathrm{~mL}) \text {. }\end{array}$ \\
\hline
\end{tabular}


Table 2 Contradications for Binocrit as specified by the EMA

Hypersensitivity to the active substance or to any of the excipients. Patients who develop pure red cell aplasia (PRCA) following treatment with any epoetin.

Uncontrolled hypertension.

Patients who for any reason cannot receive adequate antithrombotic prophylaxis.

In the indication "increasing the yield of autologous blood": myocardial infarction or stroke in the month preceding treatment, unstable angina pectoris, increased risk of deep venous thrombosis such as history of venous thromboembolic disease.

In the indication of major elective orthopedic surgery: severe coronary, peripheral arterial, carotid or cerebral vascular disease, including patients with recent myocardial infarction or cerebral vascular accident.

Abbreviation: EMA, European medicines agency.

of reporting. All EPAR and associated documents are publicly available from the EMA website. The manufacturer was not approached for information.

We describe each study in terms of objectives, endpoints, design, and patient populations studied. Therapeutic equivalence as well as other efficacy and effectiveness results from each study is reported in detail. Safety data are detailed in terms of immunogenicity, venous thrombo-embolism (VTE) and mortality, the major clinical safety issues concerning the class of erythropoiesis-stimulating agents (ESA). For other safety concerns and, in particular, those established for ESAs in general, we refer to our comprehensive review of the clinical safety of biosimilar erythropoietins. ${ }^{4}$

Immunogenicity refers to the ability of a protein antigen to elicit an immune response and the production of antibodies against the protein. Recombinant erythropoietin may stimulate the production of anti-product antibodies and the risk of this rises with dosing, length of time of treatment, and possibly route of administration. ${ }^{7-9}$ Antibodies may not have an observable effect on either endogenous or exogenous erythropoietin; they may bind to and thus attenuate or inactivate the exogenous erythropoietin, resulting in hypersensitivity reactions or they may neutralize the endogenous protein and cause pure red cell aplasia (PRCA). ${ }^{10-12}$ An increased risk for VTE is generally accepted to be a class effect for ESAs both in patients with chronic renal insufficiency and patients with cancer. ${ }^{13}$ The greater mortality risk among cancer patients treated with ESAs reported in some recent meta-analyses ${ }^{14,15}$ may be attributable to clinical practice outside evidence-based guidelines and product labels. ${ }^{13,16}$

Lastly, a key issue is the interchangeability of biosimilar and originator products. For purposes of this review, we limit interchangeability to therapeutic interchangeability, ie, that a patient can be transferred from reference product to biosimilar because the same clinical results can be expected.
We specifically exclude formulary interchangeability, ie, substitution without the knowledge or intervention of the health care professional who prescribed the reference product.

\section{Clinical studies Overview}

The late-stage clinical development program of HX575 submitted to the EMA ${ }^{6}$ included one phase 3 study of 479 renal anemia patients (INJ-9) ${ }^{17}$ and one phase 3 study of 114 cancer patients with anemia in association with chemotherapy (INJ-11). ${ }^{18}$ In addition, one article presented the findings of a trial in 337 renal anemia patients not yet receiving renal replacement therapy (INJ-17), ${ }^{19}$ another summarized the findings of a retrospective clinical audit of 152 patients in the oncology setting (for convenience, hereafter RCA), ${ }^{20}$ while another reported the results of a post-approval EMA-mandated safety commitment study (EPO-PASS). ${ }^{21}$ One paper described the background and methodology of a pharmaco-epidemiological study of HX575 in the hemodialysis setting that is still in the recruitment phase (MONITOR-CKD5). ${ }^{22}$

\section{Study INJ-9: patients with chronic renal failure receiving hemodialysis ${ }^{6,17}$ \\ Methods}

The objective of study INJ-9 was to evaluate a 1:1 dose conversion from Eprex/Erypo to HX575 in terms of clinical efficacy and safety in patients with chronic renal failure (aka end-stage renal disease or stage 5 chronic kidney disease) receiving hemodialysis. The intent was to document the therapeutic equivalence of HX575 relative to Eprex/Erypo.

The study was designed as a double-blind, multicenter, parallel group, randomized controlled trial in which hemodialysis patients being treated with Eprex/Erypo at screening/ baseline (weeks -2 to 0 ) were randomly assigned in a 2:1 scheme to switch to treatment with HX575 or continue treatment with the originator product. There were two steps following randomization. Step 1 was a period of dose adjustment and maintenance of $\mathrm{Hb}$ concentration (weeks 1 through 24), while step 2 was the evaluation period (weeks 25-28). In addition, patients were invited to participate in an open-label, observational safety extension sub-study (weeks 29-56), involving all consenting patients who received HX575, including those previously in the Eprex/Erypo arm. All patients received their study medication intravenously (IV) three times weekly.

The primary endpoint was defined as the mean absolute change in $\mathrm{Hb}$ level between the screening/baseline period, 
when all patients were treated with Eprex/Erypo, and the evaluation period after 2:1 randomization to treatment with HX575 or continued treatment with the originator product, and this for patients in the per-protocol (PP) analysis population. The equivalence margin was set as the $95 \%$ confidence interval (CI) of $\pm 0.5 \mathrm{~g} / \mathrm{dL}$ for the difference in mean absolute change in $\mathrm{Hb}$ between the treatment arms. Secondary endpoints of relevance to this review were the proportions of patients responding to treatment, the range of weekly mean $\mathrm{Hb}$ values, the proportion of patients with $\mathrm{Hb}$ in the target range of 10.0 to $13.0 \mathrm{~g} / \mathrm{dL}$ during three sub-periods of the study, and the proportion of patients requiring a blood transfusion. Two definitions of treatment response were used. The first definition specified a mean $\mathrm{Hb}$ during both the screening/baseline and evaluation periods within the 10.0 to $13.0 \mathrm{~g} / \mathrm{dL}$ target range. The second definition included the first definition but also specified that the change in mean weekly dose should be $25 \%$ or less.

Patients randomized to the Eprex/Erypo arm continued their treatment, while patients in the HX575 arm were converted to this agent at an equivalent dose. If on two consecutive weekly assessments the $\mathrm{Hb}$ level was outside the 10.0 to $13.0 \mathrm{~g} / \mathrm{dL}$ target range, investigators could increase the dose by up to $25 \%$ of the weekly dose every three weeks. The allowed maximum dose was $300 \mathrm{IU} / \mathrm{kg} /$ week and patients for whom this limit was exceeded were withdrawn from the study. In the open-label extension study (weeks 29-56), all patients were treated with HX575 at the same epoetin dose as at the end of the evaluation period (step 2, week 28).

\section{Patients}

The sample included male and female clinically stable patients who, at screening/baseline, had been receiving hemodialysis thrice weekly for at least 6 months. They were required to have had $\mathrm{Hb}$ concentrations in the target range of 10.0 to $13.0 \mathrm{~g} / \mathrm{dL}$ for at least 12 weeks and, at randomization, adequate iron status (serum ferritin $\geq 100 \mu \mathrm{g} / \mathrm{L}$ and/or transferrin saturation $\geq 20 \%$ ) and no evidence of significant inflammation (C-reactive protein $<1.5 \mathrm{mg} / \mathrm{L}$ ). Prior Eprex/ Erypo treatment had to be stable ( $<25 \%$ change in dose) for a minimum of 14 weeks prior to randomization, with a maximum dose of $300 \mathrm{IU} / \mathrm{kg} /$ week. Relevant exclusion criteria were transfusions in the past 14 weeks and any conditions interfering with erythropoietic response.

A total of 568 patients were screened, of whom 479 were randomized to either the HX575 ( $\mathrm{n}=315$ minus one patient who did not receive treatment for a total of 314 patients) or the Eprex/Erypo arms $(n=164)$.
The per-protocol evaluable patients in each arm were 207 and 118, respectively. As detailed in Table 3, the two treatment arms were similar in terms of gender, age, weight, kidney disease, time since diagnosis of chronic renal failure, and start of hemodialysis as well as dose, $\mathrm{Hb}$, and iron status at screening/baseline.

\section{Efficacy}

Table 4 summarizes the results for the primary and secondary endpoints. The difference in mean absolute change in $\mathrm{Hb}$ between the two treatment arms was not statistically significant. The difference between both means was 0.084 and the $95 \%$ CI was within the therapeutic equivalence boundaries of $\pm 0.5 \mathrm{~g} / \mathrm{dL}$. Similar proportions of patients responded to treatment with HX575 casu quo Eprex/Erypo. The range of weekly mean $\mathrm{Hb}$ values was well above $11.0 \mathrm{~g} / \mathrm{dL}$ and statistically similar between both treatment groups. The percentages of patients with $\mathrm{Hb}$ values in the target range of 10.0 to $13.0 \mathrm{~g} / \mathrm{dL}$ between weeks 1 and 28 varied between $78.5 \%$ and $89.2 \%$ in the HX575 treatment arm and between $79.8 \%$ and $90.1 \%$ in the Eprex/Erypo $\operatorname{arm}(P=\mathrm{ns})$. The percentages

Table 3 Patient characteristics in the INJ-9 study (PP population)

\begin{tabular}{|c|c|c|c|}
\hline & $\begin{array}{l}\text { HX575 } \\
(n=207)\end{array}$ & $\begin{array}{l}\text { Eprex/Erypo } \\
(\mathrm{n}=1 \mid 8)\end{array}$ & $P$ \\
\hline Gender, male (\%) & $56.0 \%$ & $61.0 \%$ & ns \\
\hline Age (years) $(M \pm S D)$ & $61.9 \pm 14.7$ & $62.1 \pm 13.3$ & ns \\
\hline Weight $(\mathrm{kg})(M \pm S D)$ & $77.8 \pm 16.0$ & $75.2 \pm 17.8$ & ns \\
\hline \multicolumn{4}{|l|}{$\begin{array}{l}\text { Primary etiology of } \\
\text { chronic renal failure }\end{array}$} \\
\hline Diabetes & $20.3 \%$ & $17.8 \%$ & \\
\hline Hypertension & $12.6 \%$ & $11.0 \%$ & \\
\hline Interstitial nephritis & $6.8 \%$ & $6.8 \%$ & \\
\hline Chronic glomerulonephritis & $23.7 \%$ & $29.7 \%$ & \\
\hline Polycystic kidney disease & $8.2 \%$ & $5.9 \%$ & \\
\hline Urologic & $4.3 \%$ & $4.2 \%$ & \\
\hline Other & $15.0 \%$ & $15.3 \%$ & \\
\hline Unknown & $9.2 \%$ & $9.3 \%$ & \\
\hline $\begin{array}{l}\text { Time since diagnosis } \\
\text { of chronic renal failure } \\
\text { (months) }(M \pm S D)\end{array}$ & $98.2 \pm 89.1$ & $82.0 \pm 71.5$ & ns \\
\hline $\begin{array}{l}\text { Time since start of } \\
\text { hemodialysis (months) } \\
\text { ( } M \pm S D \text { ) }\end{array}$ & $53.1 \pm 56.3$ & $56.0 \pm 64.6$ & ns \\
\hline \multicolumn{4}{|l|}{ At screening/baseline } \\
\hline $\begin{array}{l}\text { Exprex/Erypo dose } \\
\text { (IU/week) }(M \pm S D)\end{array}$ & $7053.9 \pm 3666.8$ & $6622.9 \pm 3629.2$ & ns \\
\hline $\mathrm{Hb}(\mathrm{g} / \mathrm{dL})(\mathrm{M} \pm \mathrm{SD})$ & $11.7 \pm 0.8$ & $11.9 \pm 0.7$ & ns \\
\hline $\begin{array}{l}\text { Serum ferritin }(\mathrm{ng} / \mathrm{mL}) \\
(M \pm S D)\end{array}$ & $655.1 \pm 397.7$ & $685.5 \pm 511.7$ & ns \\
\hline Transferrin saturation (\%) & $24.9 \pm 9.2$ & $26.3 \pm 10.5$ & ns \\
\hline
\end{tabular}

Abbreviations: IU, international units; $\mathrm{M} \pm \mathrm{SD}$, mean \pm standard deviation; PP, perprotocol. 
Table 4 Primary and secondary efficacy endpoints in the INJ-9 study (PP population)

\begin{tabular}{|c|c|c|c|}
\hline & $\begin{array}{l}H \times 575 \\
(n=207)\end{array}$ & $\begin{array}{l}\text { Eprex/Erypo } \\
(\mathrm{n}=118)\end{array}$ & $\boldsymbol{P}$ \\
\hline Mean absolute change in $\mathrm{Hb}(\mathrm{g} / \mathrm{dL})(\mathrm{M} \pm \mathrm{SE})$ & $0.147 \pm 0.092$ & $0.063 \pm 0.117$ & ns \\
\hline Difference in mean absolute change in $\mathrm{Hb}(\mathrm{g} / \mathrm{dL})$ & \multicolumn{3}{|c|}{0.084} \\
\hline $95 \% \mathrm{Cl}$ & \multicolumn{3}{|c|}{-0.170 to 0.338} \\
\hline \multicolumn{4}{|l|}{ Proportion of patients responding to treatment } \\
\hline $\begin{array}{l}\text { Per definition I: patients with mean } \mathrm{Hb} \text { during screening/baseline and during } \\
\text { evaluation period within the target range of } 10.0 \text { to } 13.0 \mathrm{~g} / \mathrm{dL}(\%, 95 \% \mathrm{Cl})\end{array}$ & $80.7 \%(74.6$ to 85.8$)$ & $81.4 \%(73.1$ to 87.9$)$ & ns \\
\hline $\begin{array}{l}\text { Per definition } 2 \text { : patients meeting definition I and with a change in mean } \\
\text { weekly dose } \leq 25 \%(\%, 95 \% \mathrm{Cl})\end{array}$ & $69.6(62.8$ to 75.8$)$ & $64.4(55.1$ to 73.0$)$ & ns \\
\hline Range of weekly mean $\mathrm{Hb}$ values $(\mathrm{g} / \mathrm{dL})$ & 11.6 to 11.9 & 11.7 to 12.1 & ns \\
\hline \multicolumn{4}{|l|}{ Proportion of patients whose $\mathrm{Hb}$ is within the target range of 10.0 to $13.0 \mathrm{~g} / \mathrm{dL}$ during } \\
\hline Weeks I through 24 & $94.2 \%$ & $95.8 \%$ & ns \\
\hline Weeks 25 through 28 & $85.5 \%$ & $84.7 \%$ & ns \\
\hline Weeks I through 28 & $29.0 \%$ & $29.7 \%$ & ns \\
\hline Proportion of patients receiving a blood transfusion & $1.0 \%$ & $0.0 \%$ & ns \\
\hline
\end{tabular}

Abbreviations: $95 \% \mathrm{Cl}, 95 \%$ confidence interval; $\mathrm{M} \pm \mathrm{SE}$, mean \pm standard error of the mean; PP, per-protocol.

of patients with mean $\mathrm{Hb}$ values $\geq 10 \mathrm{~g} / \mathrm{dL}$ during this period ranged from $91.3 \%$ to $97.0 \%$ in the HX575 group and from $92.8 \%$ to $100.0 \%$ in the Eprex/Erypo arm $(P=\mathrm{ns})$. Differences between the proportions of patients with $\mathrm{Hb}$ values within the treatment target range of 10.0 to $13.0 \mathrm{~g} / \mathrm{dL}$ were not statistically significant during the dose adjustment and $\mathrm{Hb}$ maintenance periods (step 1, weeks 1 through 24), the evaluation period (step 2, weeks 25 through 28 ), or the entire 28-week study period. Two patients in the HX575 and none in the Eprex/Erypo arm required a blood transfusion.

These results were sustained in the open-label extension study, including in the Eprex/Erypo patients converted to HX575 (EE/HX575). The HX575 patients showed mean $\mathrm{Hb}$ values from 11.6 to $11.9 \mathrm{~g} / \mathrm{dL}$ compared to 11.5 to $12.1 \mathrm{~g} / \mathrm{dL}$ for the EE/HX575 patients. Between $81.7 \%$ and $87.7 \%$ of patients in the HX575 group and $80.0 \%$ and $87.5 \%$ of patients in the Eprex/Erypo group had $\mathrm{Hb}$ values in the 10.0 to $13.0 \mathrm{~g} / \mathrm{dL}$ target range. The percentages of patients with mean $\mathrm{Hb}$ values $\geq 10 \mathrm{~g} / \mathrm{dL}$ varied between from $92.0 \%$ and $94.9 \%$ in the HX575 group and from $86.9 \%$ to $96.3 \%$ in the Eprex/ Erypo group.

Mean weekly epoetin dosage was statistically similar between both arms and constant during the entire study period with a median change of $0 \mathrm{IU} /$ week.

\section{Safety}

Two patients treated with HX575 and four patients administered Eprex/Erypo had transient non-neutralizing antibodies exceeding the cut-off value in the ribonucleoprotein immunoprecipitation (RIP) assays at 28 or 42 weeks. The two HX575-treated patients had elevated antibodies from baseline throughout the study, which was attributed to prior treatment with Eprex/Erypo. One of these patients also had a borderline positive result for neutralizing antibodies on one occasion but no other signs that indicated PRCA, though this patient required high doses of HX575. One patient in the extension study who switched from Erypo/Eprex to HX575 had a positive antibody result at week 56. No follow-up data are available, as this patient died a few months later from heart failure. None of the patients with elevated antibody titers had any signs suggestive of PRCA such as a sudden decrease in $\mathrm{Hb}$ or reticulocyte levels. Thirty-eight patients died during the study. None of these deaths were attributed to the study medications. One case was first related to study medication, but no autopsy to confirm was performed (the study medication was not reported). Eventually, the death was attributed to an embolism originating in the left ventricle secondary to protein $\mathrm{S}$ deficiency and underlying dilatative cardiomyopathy and dyskinesia. The mortality rates between the HX575 and Eprex/Erypo arms were, respectively, 8.9\% (28 of 314 patients in the HX575 safety population) and $6.1 \%$ (10 of 164), and this difference was not statistically significant. Cardiovascular diseases were the most common cause of death, occurring in 18 patients, all of whom had a prior history of cardiac disease. Additional safety data have been summarized elsewhere. ${ }^{4,6}$

Study INJ-I I: patients with solid tumors receiving antineoplastic chemotherapy ${ }^{6,18}$

\section{Methods}

The objective of study INJ-11 was to assess the clinical efficacy and safety of HX575 in the treatment of chemotherapy-associated anemia in cancer patients with solid tumors. The study was not designed as a confirmatory 
study and did not intend to assess the comparability of the efficacy and safety of HX575 relative to originator Eprex/ Erypo. Though patients were randomized to either HX575 or Eprex/Erypo, the latter study arm was included only for purposes of internal validity.

INJ-11 was designed as a double-blind, multicenter, randomized study in the oncology setting. Patients with solid tumors receiving chemotherapy were randomly assigned in a 2:1 scheme to 12 weeks of three times weekly treatment with HX575 or originator Eprex/Erypo.

The study's primary endpoint was the proportion of HX575-treated patients with an $\mathrm{Hb}$ response during weeks 5 through 12 . $\mathrm{Hb}$ response was defined as an increase in $\mathrm{Hb}$ of at least $2.0 \mathrm{~g} / \mathrm{dL}$ from the mean $\mathrm{Hb}$ value observed during the screening/baseline period with no blood transfusion in the four weeks prior. The response threshold was a lower bound greater than $30 \%$ of the $95 \%$ CI of the proportion of HX575 patients showing an $\mathrm{Hb}$ response. Relevant secondary endpoints included mean $\mathrm{Hb}$ change in the HX575 and Eprex/Erypo groups, the difference in mean change at weeks 5 and 12 between both groups, and the proportions of patients in the respective groups receiving a blood transfusion during the study period.

In keeping with standard clinical protocol at the time study INJ-11 was planned, the starting dose of study medication was $150 \mathrm{IU} / \mathrm{kg}$ body weight administered subcutaneously (SC) three times per week. The dose was increased to $300 \mathrm{IU} / \mathrm{kg}$ if, at four weeks, the $\mathrm{Hb}$ had not increased by at least $1.0 \mathrm{~g} / \mathrm{dL}$, if the reticulocyte count had not risen by at least $40,000 / \mu \mathrm{L}$, or if, at eight weeks, the increase in $\mathrm{Hb}$ was less than $2.0 \mathrm{~g} / \mathrm{dL}$. Study medication was suspended if a patient's $\mathrm{Hb}$ level exceeded $12.0 \mathrm{~g} / \mathrm{dL}$ at any time during the study period and restarted at $75 \%$ of dose when $\mathrm{Hb}$ levels were below $11.0 \mathrm{~g} / \mathrm{dL}$. The dose was also decreased to $75 \%$ if the increase in $\mathrm{Hb}$ in the first four weeks of the study surpassed $2.0 \mathrm{~g} / \mathrm{dL}$ in the absence of blood transfusion in the prior two weeks.

\section{Patients}

Eligible subjects included male and female patients with a confirmed solid tumor diagnosis receiving palliative chemotherapy and with anemia in association with chemotherapy ( $\mathrm{Hb} \leq 100 \mathrm{~g} / \mathrm{dL}$ ). Other inclusion criteria were an Eastern Cooperative Oncology Group performance status not exceeding 2, a life expectancy of at least 6 months, adequate iron status (serum ferritin $\geq 100 \mu \mathrm{g} / \mathrm{L}$ and/or transferrin saturation $\geq 20 \%$ ), adequate renal function (serum creatinine $\leq 0.023 \mathrm{mmol} / \mathrm{L}$ ), and bilirubin below
$1.5 \times$ the normal range upper limit. Key exclusion criteria were primary hematological disorders, thrombotic events in the past 6 months, suspected or known PRCA, or transfusion in the past two or ESA treatment in the past 8 weeks.

In total, 162 patients were screened, of which 114 were randomized 2:1 to treatment with HX575 $(n=74)$ or Eprex/ Erypo $(n=60)$. Due to early withdrawal, 20 patients had no $\mathrm{Hb}$ measurements during weeks 5 through 12 , leaving 94 patients in the intent-to-treat population. Of these, 60 were treated with HX575 and 34 with Eprex/Erypo. As shown in Table 5, the two subsamples were similar in gender mix, age, height and weight, primary tumor type, time since cancer diagnosis, $\mathrm{Hb}$, iron status, and performance status at screening/baseline.

\section{Efficacy}

Among HX575-treated patients, $61.7 \%$ showed an increase in $\mathrm{Hb}$ of at least $2.0 \mathrm{~g} / \mathrm{dL}$. The $95 \% \mathrm{CI}$ for this estimate was $48.2 \%$ to $73.9 \%$ (Table 6). The lower bound of this CI exceeded $30 \%$ and thus the primary endpoint was met.

The observed differences in the distribution of responders versus non-responders in the two treatment groups were statistically not significant. The mean change in $\mathrm{Hb}$ levels from baseline was $1.9 \mathrm{~g} / \mathrm{dL}$ in both treatment groups. The difference in mean $\mathrm{Hb}$ between the two groups was -1.0

Table 5 Patient characteristics in the INJ-I I study (ITT population)

\begin{tabular}{|c|c|c|c|}
\hline & $\begin{array}{l}\text { HX575 } \\
(n=60)\end{array}$ & $\begin{array}{l}\text { Eprex/Erypo } \\
(n=34)\end{array}$ & $P$ \\
\hline Gender, male (\%) & $45.0 \%$ & $61.0 \%$ & ns \\
\hline Age (years)' & 58.8 & 60.4 & $-^{2}$ \\
\hline Weight $(\mathrm{kg})(\mathrm{M} \pm \mathrm{SD})$ & $68.2 \pm 13.3$ & $66.1 \pm 9.2$ & ns \\
\hline Height (cm) $(M \pm S D)$ & $167.7 \pm 8.3$ & $168.6 \pm 9.3$ & \\
\hline Primary site of malignancy & & & ns \\
\hline Ovary & $28.3 \%$ & $20.6 \%$ & \\
\hline Lung & $21.7 \%$ & $17.6 \%$ & \\
\hline Breast & $6.7 \%$ & $5.9 \%$ & \\
\hline Pancreas & $8.3 \%$ & I I.8\% & \\
\hline Stomach & $5.0 \%$ & I I.8\% & \\
\hline Colon & $5.0 \%$ & $5.9 \%$ & \\
\hline $\begin{array}{l}\text { Time since diagnosis of cancer } \\
\text { (months) }(M \pm S D)\end{array}$ & $21.1 \pm 29.0$ & $20.4 \pm 28.8$ & ns \\
\hline \multicolumn{4}{|l|}{ At screening/baseline } \\
\hline $\mathrm{Hb}(\mathrm{g} / \mathrm{dL})(\mathrm{M} \pm \mathrm{SD})$ & $9.0 \pm 0.9$ & $9.0 \pm 0.8$ & ns \\
\hline Serum ferritin $(n g / m L)(M \pm S D)$ & $744.3 \pm 633.6$ & $978.8 \pm 969.0$ & ns \\
\hline Transferrin saturation (\%) & $38.8 \pm 36.1$ & $33.2 \pm 33.3$ & ns \\
\hline ECOG status & & & ns \\
\hline 0 & $3.2 \%$ & $11.8 \%$ & \\
\hline $\mathrm{I}$ & $60.0 \%$ & $67.6 \%$ & \\
\hline 2 & $36.7 \%$ & $20.6 \%$ & \\
\hline
\end{tabular}

Notes: 'No standard deviation reported; ${ }^{2}$ not calculable.

Abbreviations: ECOG, Eastern Cooperative Oncology Group; ITT, intent-to-treat; $\mathrm{IU}$, international units; $\mathrm{M} \pm \mathrm{SD}$, mean \pm standard deviation. 
Table 6 Primary and secondary efficacy endpoints in the INJ-II study (ITT population)

\begin{tabular}{|c|c|c|c|}
\hline & $\begin{array}{l}H \times 575 \\
(n=60)\end{array}$ & $\begin{array}{l}\text { Eprex/Erypo } \\
(\mathrm{n}=34)\end{array}$ & $\boldsymbol{P}$ \\
\hline Mean change in $\mathrm{Hb}(\mathrm{g} / \mathrm{dL})(\mathrm{M})^{\prime}$ & 1.9 & 1.9 & $--^{2}$ \\
\hline \multicolumn{4}{|c|}{ Difference in mean change in $\mathrm{Hb}(\mathrm{g} / \mathrm{dL})$} \\
\hline At 5 weeks & -1.0 & & \\
\hline $95 \% \mathrm{Cl}$ & -0.78 to 0.76 & & \\
\hline At 12 weeks & -0.9 & & \\
\hline $95 \% \mathrm{Cl}$ & -1.01 to 0.83 & & \\
\hline \multicolumn{3}{|l|}{ Proportion of patients who are } & ns \\
\hline Non-responders & $38.3 \%$ & $55.9 \%$ & \\
\hline Responders & $61.7 \%$ & $44.1 \%$ & \\
\hline $95 \% \mathrm{Cl}$ & 48.2 to 73.9 & $27.2 \%$ to $62.1 \%$ & \\
\hline $\begin{array}{l}\text { Proportion of patients receiving } \\
\text { a blood transfusion }\end{array}$ & $31.7 \%$ & $38.2 \%$ & ns \\
\hline
\end{tabular}

Notes: 'No standard deviation reported; ${ }^{2}$ not calculable. Abbreviations: $95 \% \mathrm{Cl}$, $95 \%$ confidence interval; ITT, intent-to-treat; $\mathrm{M}$, mean.

at 5 weeks and -0.9 at 12 weeks, a difference that was not statistically significant. Statistically similar proportions of patients received blood transfusions during the 12-week study period.

\section{Safety}

One patient in the HX575 group had anti-epoetin antibodies exceeding the cut-off value before the first administration of HX575. This was attributed to prior erythropoietic treatment. No antibodies were detected in any of the patients during the study. No patients showed a sudden decrease in $\mathrm{Hb}$ concentrations or reticulocyte counts. Venous thrombo-embolic events were recorded in a total of eight patients. The HX575 group counted two cases of ventricular arrhythmias/cardiac arrest and one case of peripheral embolism/thrombosis. There were also two cases of ventricular arrhythmias/cardiac arrest in the Eprex/Erypo group in addition to three cases of ischemic coronary artery disorders, of which only a non-serious acute myocardial infarct was considered either suspected or not assessable in its causal relationship to the drug. Thirty patients, including 18 in the HX575 group and 12 in the Eprex/Erypo group, died during or shortly after the study. None of these deaths were attributed to the study medications. Additional safety data have been summarized elsewhere. ${ }^{4,6}$

\section{Study INJ-I7: patients with chronic kidney disease not receiving dialysis ${ }^{19}$ \\ Methods}

Study INJ-17 was designed to evaluate the safety and immunogenicity of HX575 relative to Eprex/Erypo during long-term SC administration in patients with chronic kidney disease (CKD) stages 3 through 5 not yet on dialysis. This study was conducted because the SC license for Eprex/Erypo had been withdrawn following a rise in the incidence of PRCA in many patients treated with this agent; hence, studies such as INJ-9 and INJ-11 could not evaluate SC regimens. Study INJ-17 was intended to be a safety and not an efficacy study. The study was terminated prematurely because of two cases of neutralizing antibodies in the HX575-treated study arm. One case was confirmed subsequently as PRCA. The other case was not confirmed as PRCA as the patient had died by the time the neutralizing antibodies were detected.

INJ-17 was designed as a double-blind, multicenter, randomized controlled trial. Patients were randomly assigned in a 1:1 scheme to 52 weeks of thrice-weekly SC treatment with HX575 or originator Eprex/Erypo.

The study's primary endpoint was the safety and immunogenicity of HX575 compared to the originator product. Two post hoc efficacy endpoints were added at the time of study termination and before unblinding and data analysis: (1) mean absolute change in $\mathrm{Hb}$ from baseline through week 13 within an equivalence region of -1.0 to $+1.0 \mathrm{~g} / \mathrm{dL}$ and (2) mean weekly epoetin dosage in weeks 11 through 13 within an equivalence region of -45 to $+45 \mathrm{IU} / \mathrm{kg}$ body weight.

Patients were administered a starting dose of $25 \mathrm{IU} / \mathrm{kg}$ three times weekly or $75 \mathrm{IU} / \mathrm{kg}$ once weekly during weeks 1 through 5. After 5 weeks, this dose could be adjusted upward or downward to maintain $\mathrm{Hb}$ levels in a target range of 10 to $12 \mathrm{~g} / \mathrm{dL}$.

\section{Patients}

The sample consisted of adults with a diagnosis of stage 3,4 , or $5 \mathrm{CKD}$, anemia as evidenced by $\mathrm{Hb}$ levels between $7.5 \mathrm{~g} / \mathrm{dL}$ and $11.0 \mathrm{~g} / \mathrm{dL}$, either treatment-naïve relative to ESAs or not treated with an ESA for at least three months, and adequate iron status (serum ferritin $\geq 100 \mu \mathrm{g} / \mathrm{L}$ and/or transferrin saturation $\geq 20 \%$ ). Exclusion criteria relevant to the present review included chronic dialysis in the preceding 6 months, recent blood transfusion, suspected or known PRCA, hematological disorders including thrombocytopenia, neutropenia, or hemolysis, uncontrolled diabetes, hypertension, or hyperparathyroidism or severe liver dysfunction, congestive heart failure and/or angina, myocardial infarct or stroke in the preceding six months, acute or chronic infection, gastrointestinal bleeding in the 6 months prior, active malignancy in the previous 5 years, or immunosuppressive therapy in the previous 3 months. 
Of the 602 patients screened, 337 were randomized $1: 1$ to the HX575 $(\mathrm{n}=174)$ or the Eprex/Erypo study arm $(n=163)$. Of these, 37 patients in the HX575 and 29 patients in the Eprex/Erypo study arms completed the study protocol at the time the study was terminated. Table 7 presents the patient characteristics at baseline. The subsamples were similar in terms of gender mix, age, weight and height, primary etiology of kidney disease, and baseline $\mathrm{Hb}$ concentration.

\section{Efficacy}

As shown in Table 8, the mean change in $\mathrm{Hb}$ levels from baseline was $2.2 \mathrm{~g} / \mathrm{dL}$ in both treatment groups. The difference in mean $\mathrm{Hb}$ between the two groups was $-0.01 \mathrm{~g} / \mathrm{dL}$. The mean change in weekly dose from baseline was $51.7 \mathrm{IU} / \mathrm{kg}$ in the HX575 and $51.6 \mathrm{IU} / \mathrm{kg}$ in the Eprex/Erypo study arm (absolute doses not reported). The difference in mean weekly dose change between the two groups was $0.02 \mathrm{IU} / \mathrm{kg}$.

\section{Safety}

Results from RIP assays performed on screening data identified three patients already randomized to the HX575 treatment arm as being positive for antibodies. Tests for neutralizing antibodies (NAb) were negative. Though the RIP results may have been false-positives, these patients were withdrawn from the study. Five patients in the HX575 and two patients in the Eprex/Erypo group had positive RIP results during the treatment period of the study. Two of the RIP-positive HX575-treated patients had positive $\mathrm{NAb}$ tests. A subsequent root cause analysis identified

Table 7 Patient characteristics in the INJ-I7 study (safety population)

\begin{tabular}{llll}
\hline & $\begin{array}{l}\text { HX575 } \\
(\mathbf{n}=\mathbf{I 7 4})\end{array}$ & $\begin{array}{l}\text { Eprex/Erypo } \\
(\mathbf{n}=\mathbf{1 6 3 )}\end{array}$ & $\mathbf{P}$ \\
\hline Gender, male (\%) & $44.3 \%$ & $39.9 \%$ & $\mathrm{~ns}$ \\
Age (years)' & 64.1 & 64.9 & $-^{2}$ \\
Weight (kg) (M)' & 75.5 & 73.5 & $-^{2}$ \\
Primary etiology of chronic & & & $\mathrm{ns}$ \\
kidney disease & & & \\
$\quad$ Diabetes & $28.2 \%$ & $38.0 \%$ & \\
Hypertension & $20.7 \%$ & $17.2 \%$ & \\
Interstitial nephritis & $9.8 \%$ & $13.5 \%$ & \\
$\quad$ Chronic glomerulonephritis & $19.0 \%$ & $16.0 \%$ & \\
$\quad$ Polycystic kidney disease & $4.0 \%$ & $4.3 \%$ & \\
$\quad$ Urologic & $5.2 \%$ & $3.7 \%$ & \\
$\quad$ Other & $9.2 \%$ & $6.1 \%$ & \\
$\quad$ Unknown & $4.0 \%$ & $1.2 \%$ & \\
At screening/baseline & & & \\
$\quad$ Hb (g/dL) (M) & 9.7 & 9.9 & \\
\hline
\end{tabular}

Notes: 'No standard deviation reported; ${ }^{2}$ not calculable. Abbreviation: M, mean.
Table 8 Efficacy endpoints in the INJ-I7 study (PP population)

\begin{tabular}{llll}
\hline & $\begin{array}{c}\text { HX575 } \\
(\mathbf{n}=\mathbf{3 7})\end{array}$ & $\begin{array}{l}\text { Eprex/Erypo } \\
(\mathbf{n}=\mathbf{2 9})\end{array}$ & $\mathbf{P}$ \\
\hline Mean change in $\mathrm{Hb}(\mathrm{g} / \mathrm{dL})(\mathrm{M} \pm \mathrm{SD})$ & $2.2 \pm 0.9$ & $2.2 \pm 1.0$ & $\mathrm{~ns}$ \\
Difference in mean change & & -0.01 & \\
in $\mathrm{Hb}(\mathrm{g} / \mathrm{dL})$ & & & \\
$95 \% \mathrm{Cl}$ & & -0.21 to 0.19 \\
\hline
\end{tabular}

Abbreviations: $95 \% \mathrm{Cl}, 95 \%$ confidence interval; $\mathrm{M} \pm \mathrm{SD}$, mean \pm standard deviation; PP, per-protocol.

tungsten-mediated unfolding and aggregation of epoetin alfa in the pre-filled syringes as the likely cause. ${ }^{23}$ The five remaining RIP-positive but NAb-negative patients were considered instances of false-positive RIP results. No instances of venous thromboembolism were reported. Twenty patients died during the treatment period, none attributed to study medication, including six in the HX575 and fourteen in the Eprex/Erypo group. Additional safety data are summarized in the study's publication. ${ }^{19}$

\section{Study RCA: Patients with chronic kidney disease not receiving dialysis}

Methods

The objective of this study (for purposes of this review coded as RCA, for retrospective clinical audit) was to evaluate the effectiveness of HX575, marketed commercially as Binocrit, in the management of chemotherapy-induced anemia in cancer patients.

The study was designed as a retrospective clinical audit in five centers in Europe where Binocrit was used per these centers' internal clinical protocols in the treatment of anemia in cancer patients with solid tumors undergoing antineoplastic chemotherapy. The primary outcome parameter was $\mathrm{Hb}$ response based on the $\mathrm{Hb}$ concentrations recorded over an observation period of up to 26 weeks. Hb response was defined as an $\mathrm{Hb}$ increase of at least $1 \mathrm{~g} / \mathrm{dL}$ over four weeks of treatment or an $\mathrm{Hb}$ in the 10.0 to $12.0 \mathrm{~g} / \mathrm{dL}$ range during the study. Patients were treated with Binocrit at 30,000 IU/week or 40,000 IU/week per the patients' treating physician's best clinical judgment or center protocol. There was no comparator treatment.

\section{Patients and treatments}

In total, 152 patients meeting the requirements of an $\mathrm{Hb}$ concentration of at least $8.5 \mathrm{~g} / \mathrm{dL}$ at start of Binocrit treatment and treated for at least six weeks were included in the study. Table 9 summarizes patient and treatment characteristics. In descending order, the most prevalent cancer types were lung $(21.1 \%)$, breast and colon $(13.2 \%$ each), and 
Table 9 Patient and treatment characteristics in the RCA study $(n=152)$

\begin{tabular}{ll}
\hline Age (years) $(M \pm S D)$ & $63.2 \pm 10.8$ \\
Tumor type & \\
Ovary & $7.2 \%$ \\
Lung & $21.1 \%$ \\
Breast & $13.2 \%$ \\
Pancreas & $11.2 \%$ \\
Stomach & $5.9 \%$ \\
Colon & $13.2 \%$ \\
Bladder & $5.9 \%$ \\
Endometrial & $3.3 \%$ \\
Prostate & $2.0 \%$ \\
Other & $17.1 \%$ \\
Unknown & $1.3 \%$ \\
At screening/baseline & \\
Initial dose & \\
30,000 IU & $30.3 \%$ \\
40,000 IU & $67.8 \%$ \\
Unknown & $3.9 \%$ \\
Hb (g/dL) (M $\pm S D)$ & $9.8 \pm 0.8$ \\
During treatment & \\
Iron supplementation & \\
IV & \\
Oral & $11.2 \%$ \\
Unknown & $26.3 \%$ \\
Blood transfusion & $2.0 \%$ \\
\hline & $9.9 \%$ \\
\hline
\end{tabular}

Note: 'Recalculated to ensure uniformity with other tables in this review from rounded nondecimal percentages reported in original article.

Abbreviations: $\mathrm{IU}$, international units; $\mathrm{M} \pm \mathrm{SD}$, mean \pm standard deviation.

pancreas (11.2\%). Mean $\mathrm{Hb}$ at baseline was $9.8 \mathrm{~g} / \mathrm{dL}$. Most patients (67.8\%) received 40,000 IU of Binocrit once weekly. Approximately one-third of patients (39.5\%) received iron supplementation, mainly orally $(26.3 \%)$ and $9.9 \%$ of patients were given a blood transfusion during the observational period. The evaluable sample included 113 patients because 39 patients were started outside the $\mathrm{Hb}$ range or were treated for less than six weeks.

\section{Effectiveness}

As documented in Table 10, from a mean baseline $\mathrm{Hb}$ of $9.8 \mathrm{~g} / \mathrm{dL}$, the highest recorded mean $\mathrm{Hb}$ concentration during the study was $11.1 \mathrm{~g} / \mathrm{dL}$, a statistically significant increase. A total of $78.8 \%$ of patients in the evaluable sample and $73.7 \%$ of patients in the overall sample met the criteria for $\mathrm{Hb}$ response. Response rates were statistically similar between patients treated with $30,000 \mathrm{IU} /$ week $\left(81 \%\right.$ per publication, ${ }^{20}$ though the rounding could not be replicated) versus 40,000 IU/week (77.7\%). The treatment response rate of $92.7 \%$ among the 17 patients receiving IV iron supplementation was claimed to be significantly higher $(P<0.05)$ than the $77.7 \%$ rate among patients not receiving IV iron $77.0 \%$, but the statistical significance testing could not be replicated.
Table 10 Hemoglobin outcomes in the RCA study

\begin{tabular}{ll}
\hline Mean $\mathrm{Hb}(\mathrm{g} / \mathrm{dL})(\mathrm{M} \pm \mathrm{SD})^{\prime}$ & \\
$\quad$ Baseline & $9.8 \pm 0.8$ \\
$\quad$ Highest recorded during observation period & $11.1 \pm 1.9$ \\
Proportion of treatment non-responders and responders & \\
$\quad$ Evaluable sample $(\mathrm{n}=\mathrm{I} \mid \mathrm{3})$ & $78.8 \%$ \\
$\quad$ Responders & $21.2 \%$ \\
$\quad$ Non-responders & \\
Overall sample $(\mathrm{n}=\mid \mathrm{I} 2)$ & $73.7 \%$ \\
$\quad$ Responders & $26.3 \%$ \\
$\quad$ Non-responders & \\
Proportion of responders among patients receiving ... & \\
$\quad$ IV iron ( $\mathrm{n}=\mid \mathrm{I})$ & $92.7 \%$ \\
$\quad$ Oral, no iron, or unknown $(\mathrm{n}=135)$ & $77.0 \%$
\end{tabular}

Notes: ${ }^{\prime} P<0.000{ }^{\prime} ;{ }^{2}$ stated in article to be significant at $P<0.05$ but result could not be replicated.

Abbreviations: IV, intravenous; $M \pm S D$, mean \pm standard deviation; PP, perprotocol.

Safety

No cases of immunogenicity, venous thromboembolism, death, or serious drug-related adverse events were reported.

\section{Study EPO-PASS: patients with chronic kidney disease with or without dialysis treatment \\ Methods}

The primary objective of this post-approval safety commitment study mandated by the EMA was to monitor adverse events with a focus on thrombovascular events, malignancies, and immunogenicity. The secondary objective was to evaluate the efficacy of HX575 administered IV.

EPO-PASS was designed as a multicenter, prospective, single-arm study with a 6-month treatment period with HX575 in adult CKD patients either receiving or not receiving dialysis treatment but requiring ESA treatment for an expected period of 6 months or longer. ESA-naïve patients started with an $\mathrm{Hb}$ correction phase until the target range of $10-12 \mathrm{~g} / \mathrm{dL}$ was reached, after which they entered the maintenance phase. Patients on prior ESA treatment and with an $\mathrm{Hb}$ level in the target range were converted to HX575. HX575 was administered three times weekly unless the individual weekly dose was less than $3000 \mathrm{IU} / w k$. Dose adjustments were required to stay within the 10-12 $\mathrm{g} / \mathrm{dL}$ target range and were conducted in steps of at least four weeks and in accordance with the label.

The safety endpoint included any drug-related (in the assessment of the site investigator) adverse events, with special attention to thrombovascular events, malignancies, and immunogenicity. Efficacy endpoints included the proportion of patients with $\mathrm{Hb}$ levels in the 10-12 $\mathrm{g} / \mathrm{dL}$ target range at 
baseline and every two months thereafter and the proportion of patients receiving transfusions in each of the six months of the study period. Exploratory endpoints included, for those patients converted from other ESA therapy, dose changes from the pre-study ESA to HX575, frequency and impact of pre-study switches in ESA products and/or administration route, and the time course of mean $\mathrm{Hb}$ concentrations and HX575 dose in diabetic versus non-diabetic patients.

\section{Patients}

The sample included male and female CKD patients with or without dialysis treatment but requiring ESA treatment for an expected period of 6 months or longer. Key exclusion criteria were uncontrolled hypertension, known primary lack of efficacy, unexplained loss of effect of ESA therapy, history of anti-epoetin antibodies or PRCA, and history of aplastic anemia. A total of 1698 patients were enrolled, of which three did not receive any HX575, thus leaving a treatment (and safety) sample of 1695 subjects. Of these, 1393 (82.2\%) completed the study and 302 (17.8\%) did not. Additionally, of these subjects, 1695, and 552 (32.6\%) were excluded because of major protocol violations, leaving 1143 patients in the per-protocol subsample. The mean age of all treated patients was 61.8 years (Table 11 ). Together, the five primary etiologies of CKD listed in Table 11 accounted for $74.5 \%$ of the patients. Most $(70.5 \%)$ of patients had received prior treatment with one of the three major ESAs, either IV or SC.

Table I I Patient and treatment characteristics in the EPO-PASS study $(\mathrm{n}=1695)$

\begin{tabular}{|c|c|}
\hline Age (years) $(M \pm S D)$ & $61.8 \pm 15.4$ \\
\hline \multicolumn{2}{|l|}{ Primary etiology of chronic kidney disease } \\
\hline Diabetes & $20.3 \%$ \\
\hline Hypertension & $14.0 \%$ \\
\hline Interstitial nephritis & $8.2 \%$ \\
\hline Chronic glomerulonephritis & $24.2 \%$ \\
\hline Polycystic kidney disease & $7.8 \%$ \\
\hline $\begin{array}{l}\text { Time since diagnosis of chronic kidney disease } \\
\text { (months) }(M \pm S D)\end{array}$ & $97.9 \% \pm 99.0 \%$ \\
\hline On hemodialysis & $98.1 \%$ \\
\hline On prior ESA therapy & $92.3 \%$ \\
\hline Eprex/Erypo IV & $20.1 \%$ \\
\hline Eprex/Erypo SC & $5.4 \%$ \\
\hline NeoRecormon IV & $13.0 \%$ \\
\hline NeoRecormon SC & $12.2 \%$ \\
\hline Aranesp IV & $14.4 \%$ \\
\hline Aranesp SC & $4.9 \%$ \\
\hline $\mathrm{H} \times 575$ & $14.9 \%$ \\
\hline Other ESAs & $7.3 \%$ \\
\hline ESA-naïve & $7.7 \%$ \\
\hline
\end{tabular}

Abbreviations: $I U$, international units; $M \pm S D$, mean \pm standard deviation.

\section{Effectiveness}

As shown in Table 12, the proportion of patients with $\mathrm{Hb}$ concentrations in the target range of $10-12 \mathrm{~g} / \mathrm{dL}$ rose steadily from $57.5 \%$ at baseline to $66.8 \%$ at month 6 , though it was not reported if this was statistically significant. The proportion of transfused patients over the 6-month study period was minimal and stable. There were no statistically significant dose changes from pre-study to study if patients were administered their pre-study ESA intravenously. There was a marginally

Table I 2 Safety and efficacy results in the EPO-PASS study

\begin{tabular}{|c|c|}
\hline \multicolumn{2}{|l|}{ Proportion of patients with $\mathrm{Hb}$ in $10-12 \mathrm{~g} / \mathrm{dL}$ target range } \\
\hline Baseline & $57.5 \%$ \\
\hline Month 2 & $59.7 \%$ \\
\hline Month 4 & $64.1 \%$ \\
\hline Month 6 & $66.8 \%$ \\
\hline \multicolumn{2}{|l|}{ Proportion of patients receiving transfusions } \\
\hline Month I & $0.5 \%$ \\
\hline Month 2 & $0.7 \%$ \\
\hline Month 3 & $0.7 \%$ \\
\hline Month 4 & $0.3 \%$ \\
\hline Month 5 & $0.7 \%$ \\
\hline Month 6 & $0.4 \%$ \\
\hline \multicolumn{2}{|l|}{ Most frequent ( $\geq 0.3 \%$ ) drug-related adverse events } \\
\hline Hypertension & $2.5 \%$ \\
\hline Headache & $0.9 \%$ \\
\hline Arteriovenous fistula thrombosis & $0.4 \%$ \\
\hline Hypertensive crisis & $0.4 \%$ \\
\hline \multirow{2}{*}{\multicolumn{2}{|c|}{$\begin{array}{l}\text { Most frequent }(>0.1 \%) \text { thrombovascular events } \\
\text { (drug and not drug-related) }\end{array}$}} \\
\hline & \\
\hline Arteriovenous fistula thrombosis & $3.0 \%$ \\
\hline Angina pectoris & $1.6 \%$ \\
\hline Shunt thrombosis & $1.2 \%$ \\
\hline Shunt stenosis & $0.8 \%$ \\
\hline Cardiac arrest & $0.6 \%$ \\
\hline Myocardial infarction & $0.6 \%$ \\
\hline Cerebrovascular accident & $0.5 \%$ \\
\hline Shunt occlusion & $0.5 \%$ \\
\hline Arteriovenous fitsula site complication & $0.4 \%$ \\
\hline Sudden death & $0.4 \%$ \\
\hline Venous thrombosis & $0.4 \%$ \\
\hline Acute coronary syndrome & $0.3 \%$ \\
\hline Acute myocardial infarction & $0.2 \%$ \\
\hline Arteriovenous fistula occlusion & $0.2 \%$ \\
\hline Myocardial ischemia & $0.2 \%$ \\
\hline Transient ischemic attack & $0.2 \%$ \\
\hline Catheter related complication & $0.2 \%$ \\
\hline Cerebral ischemia & $0.2 \%$ \\
\hline Ischemic cardiomyopathy & $0.2 \%$ \\
\hline Ischemic stroke & $0.2 \%$ \\
\hline \multicolumn{2}{|l|}{ Malignant disease } \\
\hline History of malignancy at study entry & $0.4 \%$ \\
\hline Diagnosed during study & $0.9 \%$ \\
\hline \multicolumn{2}{|l|}{ Death } \\
\hline During study & $4.8 \%$ \\
\hline Shortly after study & $0.6 \%$ \\
\hline Cause of death suspected to be treatment-related & $0.06 \%$ \\
\hline
\end{tabular}


significant $(P=0.0422)$ dose increase in HX575 among patients converted from subcutaneously administered ESA. The number of pre-study ESA switches was not associated with HX575 treatment outcomes.

\section{Safety}

No cases of immunogenicity were reported. Adverse events attributed to HX575 included hypertension and hypertensive crisis (combined frequency of $2.9 \%$ ), headache $(0.9 \%)$, and AV fistula thrombosis $(0.4 \%)$. Major thrombovascular events, with a frequency greater than $0.1 \%$, regardless of whether these were judged to be drug-related, ranged in frequency from AV fistula thrombosis $(3.0 \%)$ to ischemic stroke $(0.2 \%)$. None of the malignancies diagnosed during the study $(0.9 \%)$ were attributed to HX575, nor were any of the observed deaths.

\section{Comments}

The studies submitted as part of the EMA authorization process as well as the peer-reviewed reports on these and subsequent post-approval studies provide adequate evidence regarding the therapeutic equivalence of HX575 relative to originator epoetin alfa. Therapeutic equivalence was demonstrated in the renal and oncology settings, though with some qualifications as discussed below. Importantly, the dosing regimens and target $\mathrm{Hb}$ ranges reflected standard clinical practices at the time these studies were conceived. Dose increases and decreases were embedded in the treatment protocols. Treatment protocols were not confined to the dosing regimens in early clinical trials on Eprex/Erypo. In more recent studies, the upper boundary of the target $\mathrm{Hb}$ range was lowered to $12.0 \mathrm{~g} / \mathrm{dL}$, generally keeping with the revised label for ESAs. Thus, the studies reviewed here featured treatment protocols that evolved from the initial trials by integrating additional scientific evidence acquired over years of erythropoietic therapy.

In the renal setting, the comparative trial design of the INJ-9 study permitted direct inferences about the therapeutic equivalence of HX575 administered IV relative to Eprex/Erypo IV in the $\mathrm{Hb}$ maintenance phase of anemia management, and this in the population of renal patients on hemodialysis. Study INJ-17, which the sponsor (correctly) terminated because of two incident cases of neutralizing antibodies, could have provided therapeutic equivalence data in the pre-dialysis population, even though this study was initially designed as a safety trial for the SC formulation. The post hoc analyses on the patients who completed the treatment phase, despite the limited sample size and hence modest but sufficient estimates of precision, indicate therapeutic equivalence of the $\mathrm{SC}$ formulation in patients with chronic kidney disease not yet requiring renal replacement therapy. The approved renal label for Binocrit also includes pediatric patients on hemodialysis and adult patients on peritoneal dialysis. Neither study INJ-9 nor studies INJ-17 and EPO-PASS included these populations and the indications must have been granted by extrapolation from the originator product.

In the oncology setting, study INJ-11 documented therapeutic equivalence of HX575 relative to Eprex/Erypo in patients with solid tumors and chemotherapy-associated anemia. The inference of therapeutic equivalence is indirect as INJ-11 was not designed as a comparative study and the Eprex/Erypo arm was included only for purposes of internal validity. The order of magnitude of the observed $\mathrm{Hb}$ change was of similar order of magnitude and precision as that in the renal INJ-11 study. The approved cancer label for Binocrit also covers patients with malignant lymphoma and myeloma. These hematological malignancy indications must have been granted by extrapolation as well.

Extrapolation may also have been applied in the inclusion, in the label, of the transfusion-related indications. These cover patients in autologous pre-donation transfusion programs as well as moderately anemic patients undergoing major elective orthopedic surgery with expected moderate blood loss to reduce their exposure to allogeneic blood transfusions.

It would provide additional evidence and assurances if studies covered all aspects of an approved label, not only in the case of HX575 but also for all biosimilars present and future. This issue is important in the USA as the Food and Drug Administration proceeds to establishing a pathway for the approval of biosimilars. Scientific requirements for biosimilars should strike a scientific balance between therapeutic equivalence data in the major target populations and (assuming no safety evidence to the contrary) judicious regulatory extrapolations to secondary indications. In the case of biosimilar erythropoietin, if not the class of ESAs at large, there is abundant evidence from controlled efficacy and observational effectiveness studies to warrant the extrapolation seen in the EMA-approved labels.

Ideally, marketing authorization should be an impetus for manufacturers to independently initiate large-sample prospective observational follow-on studies to continue documentation of the effectiveness of their approved biosimilar product. Sandoz/Novartis has initiated such a study in the hemodialysis setting in eleven European countries. ${ }^{22}$ Arguing that it is not only important to examine effectiveness 
in terms of whether Binocrit works in hemodialysis patients, the MONITOR-CKD5 study has adopted a comprehensive framework for observational effectiveness studies that addresses the equally important questions of when Binocrit works and when it does not, in whom Binocrit works and in whom it does not, why Binocrit works in some patients but not in others, why Binocrit works with some clinicians but not with others, and why Binocrit is tolerated by some patients but not by others.

As the last question implies, the value of prospective observational studies is in the continued safety monitory that these studies enable. The safety evidence in the studies reviewed provides sufficient evidence about the safety of HX575 in terms of known and common adverse events and, importantly, the critical issues of venous thrombo-embolism and mortality. ${ }^{4}$ Regarding immunogenicity, the safety of the $\mathrm{SC}$ route of administration requires further study; hence, the route is limited to IV administration as indicated on the HX575 label.

As we have argued elsewhere about the three EMAapproved biosimilar erythropoietins collectively, registration studies (whether for originator or biosimilar agents) generally have seldom statistical power to detect low-frequency safety issues. ${ }^{4}$ Here, too, some extrapolation based on prior safety knowledge about originators is appropriate, especially since the incidence of major safety issues such as immunogenicity (for the IV route), venous thromboembolism, and mortality was not higher than what is known about epoetin alfa and the ESA in general. A challenge at this time, however, remains the frequency of known serious and severe safety events for ESAs for which the HX575 studies provide as of yet little evidence. The EPO-PASS provides important safety data in the CKD population with 770 patientyears studies. Notably, despite the two cases on neutralizing antibodies in study INJ-17, there are no recorded cases of PRCA with commercially available Binocrit.

Based on the available therapeutic equivalence and safety data, in routine clinical practice, the clinical and safety outcomes of treatment HX575 can be expected to be similar to those of the originator product Eprex/Erypo. Both products can be considered interchangeable in the management of anemia in the approved indications: patients transferred from reference product to biosimilar can be expected to show the same efficacy and safety outcomes. In keeping with EMA guidance regarding traceability, it is recommended that clinicians document the product prescribed by its commercial name. This should be a mandatory policy in any instance where patients are switched from one erythropoietin to another.
Finally, HX575 has not been compared to SB309 (Retacrit, Hospira) ${ }^{24}$ or XM01 (Eporatio, Teva), ${ }^{25}$ the two other EMA-approved biosimilar erythropoietins. Hence, there is no evidence regarding the therapeutic equivalence and safety between these three agents, and these three products should not be considered interchangeable among themselves. This also applies to epoetin beta, methoxy polyethylene glycol-epoetin beta, and darbepoetin alfa.

\section{Conclusion}

The therapeutic equivalence and safety of HX575 was evaluated through two studies included in the EMA approval dossier as well as two subsequent post-approval studies. While continued assessment of effectiveness and safety is desirable, treatment with HX575 should produce similar patient outcomes within similar safety parameters. Commercial Binocrit and Eprex/Erypo are interchangeable products, and patients transferred from reference product to biosimilar are expected to show the same clinical results.

\section{Acknowledgments}

Ivo Abraham was supported as Program Director of the AzAHEC Interprofessional Fellowship Program in Clinical Outcomes and Comparative Effectiveness Research, funded by the Bureau of Health professions, US Department of Health and Human Services.

\section{Disclosure}

The authors are principals of Matrix45, and were with the Epsilon Group, prior to that, both of which have received research grants and contracts related to erythropoietic proteins from Johnson \& Johnson $\left(\right.$ Eprex $\left.^{\circledR}\right)$, Roche $\left(\right.$ NeoRecormon $^{\circledR}$ and Mircera $\left.{ }^{\circledR}\right)$, Amgen (Epogen ${ }^{\circledR}$ and Aranesp $^{\circledR}$ ), and Sandoz/Novartis (Binocrit ${ }^{\circledR}$ ). By company policy, they cannot hold equity in sponsor organizations except through mutual funds, nor receive direct personal benefits, financial or other, from sponsor organizations. Matrix45 is currently contracted for scientific consulting services with Sandoz/Novartis on an observational study (MONITOR-CKD5) involving Binocrit ${ }^{\circledR}$ in the hemodialysis setting. Both authors are involved in this project. Matrix45 provides similar services to other biopharmaceutical companies without exclusivity constraints. The present paper is not within the scope of the Sandoz/Novartis contract and was prepared independently from both project and sponsor. The manufacturer was not contacted for data, publications, or other sources of information, nor did it have any input on the review activities or in the preparation of the manuscript. 


\section{References}

1. Lin FK, Suggs S, Lin CH, et al. Cloning and expression of the human erythropoietin gene. Proc Natl Acad Sci U S A. 1985;82(22): 7580-7584.

2. Eschbach JW, Egrie JC, Downing MR, Browne JK, Adamson JW. Correction of the anemia of end-stage renal disease with recombinant human erythropoietin. Results of a combined phase I and II clinical trial. N Engl J Med. 1987;316(2):73-78.

3. Schellekens H. How similar do 'biosimilars' need to be? Nature Biotechnol. 2004;22(11):1357-1359.

4. Abraham I, MacDonald K. Clinical safety of biosimilar recombinant human erythropoietins. Expert Opin Drug Saf. In press; 2012.

5. Brinks V, Hawe A, Basmeleh AH, et al. Quality of original and biosimilar epoetin products. Pharm Res. 2011;28(2):386-393.

6. http://www.ema.europa.eu/ema/index.jsp?curl=pages/medicines/ human/medicines/000725/human_med_000675.jsp\&murl=menus/ medicines/medicines.jsp\&mid=WC0b01ac058001d125. Accessed April 25, 2012.

7. Schellekens H. Biosimilar therapeutics-what do we need to consider? NDT Plus. 2009;2(Suppl 1):i27-i36.

8. Ryff JC, Schellekens H. Immunogenicity of rDNA-derived pharmaceuticals. Trends Pharmacol Sci. 2003;23(6):254-256.

9. Porter S. Human immune response to recombinant human proteins. J Pharm Sci. 2001;90(1):1-11.

10. Gershon SK, Luksenburg H, Coté TR, Braun MM. Pure red cell aplasia and recombinant erythropoietin. N Engl J Med. 2002;346(20): 1584-1585.

11. Bennett CL, Luminari S, Nissenson AR, et al. Pure red cell aplasia and epoetin therapy. N Engl J Med. 2004;351(14):1403-1408.

12. Schellekens H. Immunologic mechanisms of EPO-associated pure red cell aplasia. Best Pract Res Clin Haematol. 2005;18(3):473-480.

13. Aapro M. An update on twenty years of anemia management with erythropoiesis-stimulating agents in nephrology and oncology/ hematology. Oncologist. 2009;14 Suppl 1:1-5.

14. Bennett CL, Silver SM, Djulbegovic B, et al. Venous thromboembolism and mortality associated with recombinant erythropoietin and darbepoetin administration for the treatment of cancer-associated anemia. JAMA. 2008;299(8):914-924.

15. Bohlius J, Schmidlin K, Brillant C, et al. Recombinant human erythropoiesis-stimulating agents and mortality in patients with cancer: a meta-analysis of randomised trials. Lancet. 2009;373(9674): $1532-1542$.
16. Aapro MS, Birgegård G, Bokemeyer C, et al. Erythropoietins should be used according to guidelines. Lancet Oncol. 2008;9(5):412-413.

17. Haag-Weber M, Vetter A, Thyroff-Friesinger U; INJ-Study Group. Therapeutic equivalence, long-term efficacy and safety of HX575 in the treatment of anemia in chronic renal failure patients receiving hemodialysis. Clin Nephrol. 2009;72(5):380-390.

18. Weigang-Köhler K, Vetter A, Thyroff-Friesinger U. HX575, recombinant human epoetin alfa, for the treatment of chemotherapyassociated symptomatic anemia in patients with solid tumours. Onkologie. 2009;32(4):168-174.

19. Haag-Weber M, Eckardt KU, Hörl WH, Roger SD, Vetter A, Roth K. Safety, immunogenicity, and efficacy of subcutaneous biosimilar epoetin- $\alpha$ (HX575) in non-dialysis patients with renal anemia: a multicentre, randomized, double-blind study. Clin Nephrol. 2012;77(1):8-17.

20. Kerkhofs L, Boschetti G, Lugini A, Stanculeanu DL, Palomo AG. Use of biosimilar epoetin to increase hemoglobin levels in patients with chemotherapy induced anemia: real-life clinical experience. Future Oncol. 2012;8(6):751-756.

21. Hörl WH, Locatelli F, Haag-Weber M, Ode M, Roth K; Epo-PASS study group. Propspective multicenter study of HX575 (biosimilar epoetin- $\alpha$ ) in patients with chronic kidney disease applying a target hemoglobin of 10-12 g/dL. Clin Nephrol. 2012;78(1):24-32.

22. Gesualdo L, London G, Turner M, et al. A pharmacoepidemiological study of the multi-level determinants, predictors, and clinical outcomes of biosimilar epoetin alfa for renal anemia in hemodialysis patients: background and methodology of the MONITOR-CKD5 study. Intern Emerg Med. 2011. Epub May 18, 2011. doi:10.1007/511739-0110622-7.

23. Seidl A, Richter M, Fischer R, et al. Tungsten-mediated unfolding and aggregation of epoetin alfa in prefilled syringes as root cause for the occurrence of neutralising antibodies in an investigational clinical trial of subcutaneous administration. Pharm Res. 2011. Epub November 18, 2011; doi:10.1007/s11095-011-0621-4.

24. For SB309: http://www.ema.europa.eu/ema/index.jsp?curl=pages/ medicines/human/medicines/000872/human_med_001031. jsp\&mid=WC0b01ac058001d124. Last accessed April 25, 2012.

25. For XM01: http://www.ema.europa.eu/ema/index.jsp?curl=pages/ medicines/human/medicines/001033/human_med_001204. jsp\&mid=WC0b01ac058001d124. Last accessed April 25, 2012.
Biosimilars

\section{Publish your work in this journal}

Biosimilars is an international, peer-reviewed, open access journal focusing on the manufacture, development and medicinal use of biopharmaceutical compounds considered similar to an innovator agent. Specific topics covered in the journal include: Regulatory issues and pathways; manufacturing processes; chemical composition and

\section{Dovepress}

structure; quality and purity; patent issues; bioequivalence and interchangeability; clinical efficacy data; patient perspectives. The manuscript management system is completely online and includes a very quick and fair peer-review system. Visit http://www.dovepress.com/ testimonials.php to read real quotes from published authors. 